\title{
Temporal bone verrucous carcinoma: outcomes and treatment controversy
}

\author{
Mia E. Miller • Neil Martin • Guy F. Juillard • \\ Sunita Bhuta $\cdot$ Akira Ishiyama
}

Received: 28 January 2010/Accepted: 6 May 2010/Published online: 26 May 2010

(c) The Author(s) 2010. This article is published with open access at Springerlink.com

\begin{abstract}
Verrucous carcinoma is a rare tumor that presents in the head and neck with the most common sites being the oral cavity and larynx. Fourteen cases of verrucous carcinoma of the temporal bone have been described in literature; this study aims to examine treatment outcomes and discuss the controversy surrounding postoperative radiation. The study design included a literature review along with individual case report in the setting of a tertiary care medical center. Outcome analysis of all cases of verrucous carcinoma of the temporal bone, which are documented in the English literature, and presentation of a single patient report including gross, histologic and radiologic analyses were performed. The longest recorded survival for verrucous carcinoma of the temporal bone occurs in patients treated with surgery alone. Poorer outcomes for patients treated with adjuvant (chemo)radiation may be due to more advanced stage of disease at the time
\end{abstract}

Accepted for presentation at the Combined Sections Meeting of the Triological Society, Orlando, Florida, 4-7 February 2010.

M. E. Miller $(\bowtie) \cdot$ A. Ishiyama

Department of Head and Neck Surgery,

David Geffen School of Medicine at UCLA, CHS 62-237,

10833 Le Conte Ave, Los Angeles, CA 90095, USA

e-mail: miaedwards@mednet.ucla.edu

\section{N. Martin}

Department of Neurosurgery, UCLA,

Los Angeles, CA, USA

G. F. Juillard

Department of Radiation Oncology, UCLA,

Los Angeles, CA, USA

S. Bhuta

Department of Pathology and Laboratory Medicine,

UCLA, Los Angeles, CA, USA of treatment. Early reports of radiation leading to tumor dedifferentiation or early recurrence are not supported by more recent studies. Whether adjuvant radiation therapy is indicated in verrucous carcinoma of the temporal bone remains controversial.

Keywords Verrucous carcinoma - Temporal bone . Adjuvant radiation

\section{Introduction}

Verrucous carcinoma is a rare variant of squamous cell carcinoma that presents in the head and neck with the most common sites being the oral cavity and larynx [1-8]. It is so uncommon, in fact, that verrucous carcinoma composes only $5 \%$ of tumors at these sites $[2,14]$. It represents $1-4 \%$ of laryngeal malignancies [9], and the most common laryngeal subsite is the vocal cords. Other sites in the head and neck have been reported, including the paranasal sinuses [10], scalp [11], nasopharynx [12], and esophagus [13]. This cancer also has been associated with tobacco use, alcohol use, and poor oral hygiene.

Histologically, verrucous carcinoma is a wart-like lesion and displays keratosis and parakeratosis [14]. The thickened squamous epithelium gives it its characteristic church spire appearance. Although its histology is seemingly benign with "pushing" borders, it follows an insidious clinical course with aggressive local invasion and lymph node metastasis. The presence of submucous fibrosis and leukoplakia are associated with poor outcomes [15].

Verrucous carcinoma extremely rarely involves the temporal bone, and only 14 cases have been reported in literature [3, 16-24]. Because so few cases of verrucous carcinoma involving the middle ear and temporal bone 
Fig. 1 Axial (a) and coronal (b) CT scan of the temporal bone demonstrating soft tissue density with extension from the right external auditory canal to the right epitympanum, mesotympanum, and hypotympanum with dehiscence of the overlying right tegmen tympani and absence of the right ossicular chain

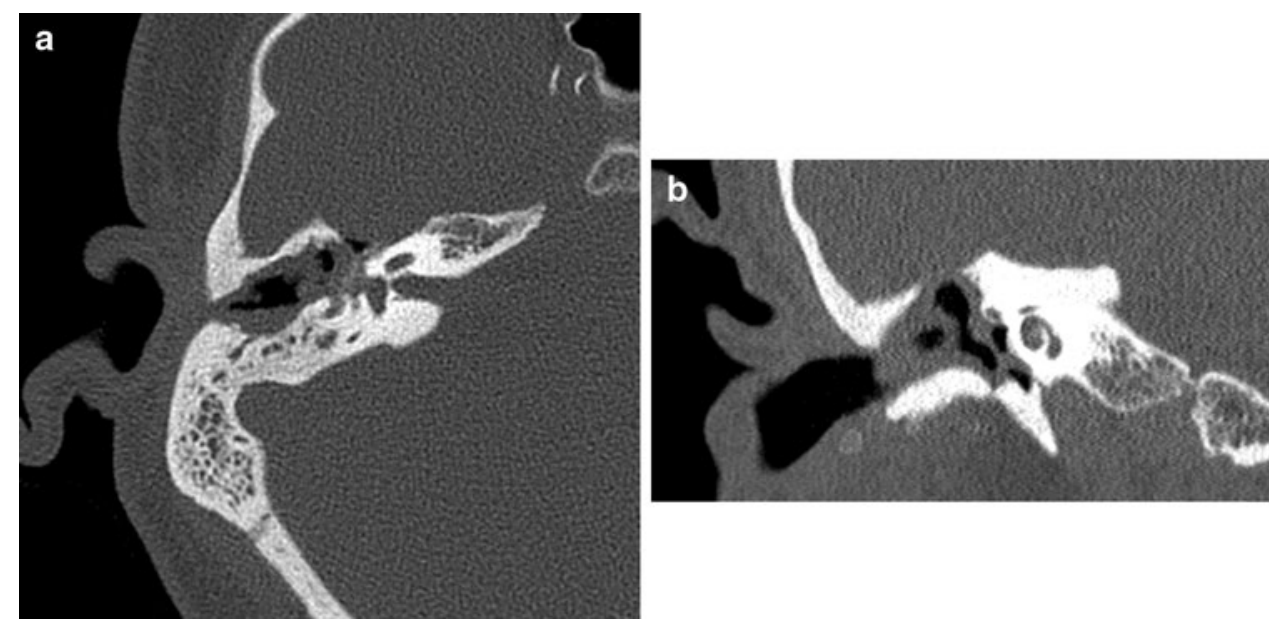

have been described, there is no consensus on the best course of treatment for these lesions. We discuss the outcomes of patients described in each of these studies, present an additional case of verrucous carcinoma of the temporal bone with skull base invasion, and discuss the treatment controversy surrounding adjuvant radiotherapy.

\section{Materials and methods}

Studies were identified by a search of the Pubmed electronic database for 'verrucous' and 'temporal bone', or 'ear'. Only studies published in the English literature were included. Ten case reports and series were identified, including a total of 14 patients with verrucous carcinoma of the temporal bone. Treatment modality, patient outcome including time to disease-specific death, and previous otologic surgery were recorded. Additional case report information from the current study was added to these results.

\section{Results}

\section{Case report}

A 51-year-old male presented with a 6-month history of a growing right external auditory canal mass. He had associated right-sided otalgia, subjective right-sided hearing loss, and occasional right-sided tinnitus. Just before presentation, he developed a right otitis externa, which improved with topical antibiotic ear drops and oral antibiotics. He denied any vertigo, headaches, or vision changes.

The patient had a 40 pack-year smoking history and a history of extensive intravenous drug use. Past medical history was otherwise noncontributory. On examination,
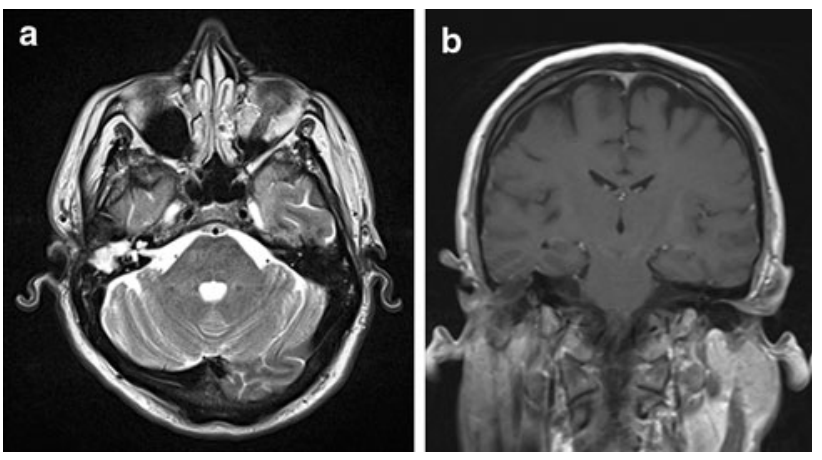

Fig. 2 Axial T2-weighted MRI (a) on a 1.5 T MRI demonstrating a soft tissue mass originating in the right external auditory canal and middle ear with dehiscence of the right tegmen tympani. Coronal T1weighted MRI (b) showing extension superiorly into the right middle cranial fossa where the mass abuts the dura at the inferior aspect of the right inferolateral temporal lobe

the patient was found to have a fungating mass originating from the posterolateral portion of the right external auditory canal. He had no lymphadenopathy, and the facial nerve was intact bilaterally.

$\mathrm{CT}$ of the temporal bone showed a right mastoid defect and absence of the ossicles (Fig. 1). Soft tissue was present in the mesotympanum and epitympanum. The residual right sclerotic temporal bone was under-pneumatized and completely opacified. MRI of the internal auditory canals demonstrated complete opacification of the right middle ear cavity and right mastoid defect (Fig. 2). The mass extended superiorly into the right middle cranial fossa where it abutted the dura at the inferior aspect of the right inferolateral temporal lobe. The mass also seemed to invade the more lateral limb of the lateral semicircular canal. No abnormalities of the bilateral internal auditory canals or cerebellopontine angles were appreciated.

Biopsy of the right external auditory canal mass was consistent with verrucous carcinoma. The patient underwent right superficial parotidectomy, mastoidectomy, 


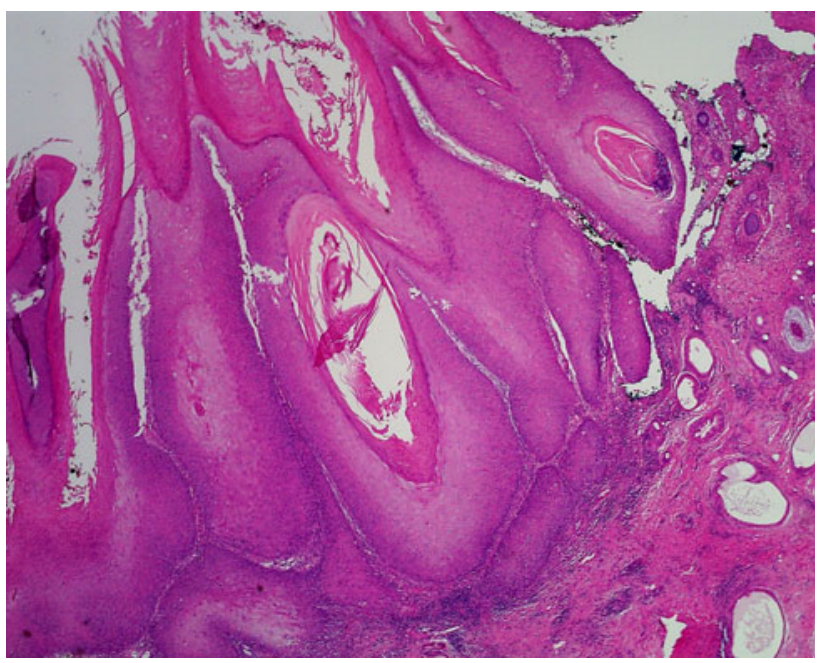

Fig. 3 Verrucous carcinoma showing marked exophytic growth with keratinization, and a broad rounded rete extending deep into the underlying collagen

labyrinthectomy, temporal bone resection, and right temporal craniotomy for resection of this tumor. Because the mass extended intracranially, the involved dura was resected and repaired with rotated temporoparietal fascia. Pathology again revealed verrucous carcinoma (Fig. 3). He did not receive postoperative radiation. He continues to do well postoperatively.

\section{Literature analysis}

We present the 15th patient in the English literature with verrucous carcinoma of the temporal bone. Of the 14 cases previously reviewed, information regarding treatment and outcome is available in 12 (Table 1). Of the five patients treated with surgery alone, two resulted in early disease- specific death. Interestingly, Edelstein et al. [19] describe a period of survival of 4-10 years in three of these patients. Kletzker et al. [24] also describe a patient who was disease free 3 years after surgery. Two patients were treated with surgery and radiation therapy: one died soon after treatment and the other did not have recorded follow-up. Three patients were treated with surgery and chemoradiation; of these two died soon after treatment and one was alive at 18 months.

\section{Discussion}

Verrucous carcinoma is most commonly diagnosed in the oral cavity (55.9\%) and the larynx (35.2\%) [25] and has a good prognosis when treated early with local excision [26]. As previously described, verrucous carcinoma is a benignappearing lesion with "pushing" borders, and the basement membrane can appear to be intact [27]. This histology often presents a diagnostic challenge, as the differential diagnosis includes pseudoepitheliomatous hyperplasia, squamous papilloma, keratosis, and verrucous hyperplasia $[28,29]$. In fact, a significant number of cases require multiple biopsies for definitive diagnosis [9], and coordination between the surgeon and pathologist is critical for accurate and timely diagnosis [30].

Although early lesions are usually treated with local excision, controversy remains regarding the optimal course of treatment for more advanced lesions. It is generally accepted that radiation is not as effective as surgery in the initial treatment of verrucous carcinoma [31]; however, the effectiveness of radiation used as adjuvant treatment remains a topic of debate.

Traditionally, possible risks have been suggested to be associated with adjuvant radiation therapy for verrucous
Table 1 Patient treatment and outcome in all cases and case series published in the English literature
Previous mastoidectomy on the side of the verrucous carcinoma, treatment modality, and length of survival or time to diseasespecific death after treatment were recorded

$N / a$ studies without available information, $D S D$ diseasespecific death

\begin{tabular}{llll}
\hline Study & Previous mastoidectomy & Treatment & Survival \\
\hline Ferlito et al. [3] & n/a & n/a & n/a \\
Pleat et al. [16] & Yes & Surgery & 2 months to DSD \\
Woodson et al. [17] & No & Surgery + xrt & n/a \\
Proops et al. [18] & Yes & Surgery + chemoxrt & 18 months follow-up \\
Edelstein et al. [19] & No & Surgery & 10 year follow-up \\
& No & Surgery & 5 year follow-up \\
& No & Surgery & 4 year follow-up \\
& Yes & Surgery + chemoxrt & 11 months to DSD \\
Piengdoh et al. [20] & Yes & Surgery + chemo & 1 year to DSD \\
Farrell and Dowe [21] & Yes & Surgery & 6 months to DSD \\
Hagiwara et al. [22] & n/a & Surgery + xrt & 8 months to DSD \\
Aydogan et al. [23] & Yes & n/a & n/a \\
Kletzker et al. [24] & Yes & Surgery & 26 months follow-up \\
\hline
\end{tabular}


carcinoma, including increased rates of distant metastasis, anaplastic transformation, and dedifferentiation of tumors. Reports of anaplastic transformation and an increase in nodal metastases come largely from earlier communications (prior to the early 1990s) [32-35]. More recent reports have not confirmed these results $[3,9,23,36,37]$. Maurizi et al. [38] raised a concern about early recurrence as they found that in the treatment of 31 patients with verrucous carcinoma of the larynx, radiation therapy in addition to surgery was associated with an early recurrence in two of seven patients treated with both modalities. However, this study was limited by its small sample size. A recent report suggests that dedifferentiation can occur not only after radiation, but also before treatment and after surgery alone [39].

In 1998, the Mayo Clinic reviewed 52 cases of laryngeal verrucous carcinoma and concluded that radiotherapy can be used effectively as an adjunct to surgical resection to preserve laryngeal function [40]. Only one of four patients in this series treated with radiotherapy to control residual disease developed a recurrence, and none showed dedifferentiation or distant metastasis after radiation treatment.

Although more current reports do not indicate that adjuvant radiation incurs increased risk of dedifferentiation, there are very few reports that describe treated cases of verrucous carcinoma of the temporal bone [3, 16-24]. We present the 15th patient with this disease described in the English literature. Aydogan et al. [23] most recently reviewed cases of verrucous carcinoma, but did not include the data of Kletzker et al. [24]. The majority of patients described in the literature had a history of chronic otitis media with aural drainage, and 7 of 14 patients had a history of previous mastoid surgery. These findings support the role of chronic irritation in the etiology of verrucous carcinoma, as discussed by Aydogan et al. [23].

Because of the lack of cases described at this anatomic site, prognostic information on adjuvant radiation after surgery is limited. Of the 12 cases described in the literature in which information regarding patient outcome is available, the longest recorded survival is in patients treated with surgery alone; however, this may be due to an earlier stage of disease and/or more aggressive surgical treatment. As described above, Edelstein et al. [19] demonstrate a period of survival of 4-10 years in three of five of these patients. Although patients treated with adjuvant radiotherapy and/or chemotherapy did not have comparable survival, this difference could be due to more advanced disease at presentation.

In the presented case, radical resection of the tumor was not followed by radiation, as clear margins were achieved at surgery. In more typical variants of squamous cell carcinoma of the temporal bone, adjuvant radiation therapy has been advocated in an attempt to increase local control rates [41]. However, studies indicate a high rate of recurrence for advanced lesions despite the use of adjuvant radiotherapy, and the 5-year survival remains poor [42]. Although radiation is not as successful in treatment of verrucous carcinoma of the larynx as ordinary invasive squamous cell carcinoma, it has been shown to be very effective when used for laryngeal preservation and in surgical salvage after surgery with positive margins [36]. Extrapolating from these data, it is reasonable to use adjuvant radiation for temporal bone verrucous carcinoma in cases with gross or microscopic positive margins.

\section{Conclusion}

Until further data are available on therapeutic outcomes of verrucous carcinoma of the temporal bone, aggressive surgery will remain the mainstay of treatment. Although adjuvant radiation does not increase the risk of recurrence or dedifferentiation, its efficacy in the treatment of verrucous carcinoma of the temporal bone has not been clearly demonstrated. In view of treatment strategies for verrucous carcinoma at different anatomic sites and for ordinary squamous cell carcinoma of the temporal bone, the treating physician may decide to use radiation in cases of temporal bone verrucous carcinoma with positive surgical margins. Novel treatment strategies have also been proposed, such as the use of palliative radiation in advanced cases, given the significant morbidity of surgery and universally poor outcomes [16].

\section{Conflict of interest statement None.}

Open Access This article is distributed under the terms of the Creative Commons Attribution Noncommercial License which permits any noncommercial use, distribution, and reproduction in any medium, provided the original author(s) and source are credited.

\section{References}

1. Kraus FT, Perezmesa C (1966) Verrucous carcinoma: clinical and pathologic study of 105 cases involving oral cavity, larynx and genitalia. Cancer 19:26-38

2. Fonts EA, Greenlaw RH, Rush BF, Rovin S (1969) Verrucous squamous cell carcinoma of the oral cavity. Cancer 23:152-160

3. Ferlito A, Recher G (1980) Ackerman's tumor (verrucous carcinoma) of the larynx: a clinicopathologic study of 77 cases. Cancer 46:1617-1630

4. McCoy JM, Waldron CA (1981) Verrucous carcinoma of the oral cavity. A review of forty-nine cases. Oral Surg Oral Med Oral Pathol 52:623-629

5. Batsakis JG, Hybels R, Crissman JD, Rice DH (1982) The pathology of head and neck tumors: verrucous carcinoma. Head Neck Surg 5:29-38

6. McDonald JS, Crissman JD, Gluckman JL (1982) Verrucous carcinoma of the oral cavity. Head Neck Surg 5:22-28 
7. Medina JE, Dichtel W, Luna MA (1984) Verrucous-squamous carcinomas of the oral cavity. A clinicopathologic study of 104 cases. Arch Otolaryngol 110:437-440

8. Rajendran R, Varghese I, Sugathan CK, Vijayakumar T (1988) Ackerman's tumour (verrucous carcinoma) of the oral cavity: a clinico-epidemiologic study of 426 cases. Aust Dent J 33:295298

9. Strojan P, Smid L, Cizmarevic B, Zagar T, Auersperg M (2006) Verrucous carcinoma of the larynx: determining the best treatment option. Eur J Surg Oncol 32:984-988

10. Yiotakis J, Vamvakidis T, Iakovou E, Manolopoulos L (2009) Aggressive verrucous carcinoma of the paranasal sinuses invading the orbit: case report and literature review. J Laryngol Otol 123(11):e23

11. Pattee SF, Bordeaux J, Mahalingam M, Nitzan YB, Maloney ME (2007) Verrucous carcinoma of the scalp. J Am Acad Dermatol 56(3):506-507

12. Jahn AF, Walter JB, Farkashidy J (1980) Verrucous carcinoma of the nasopharynx. A clinicopathologic case report. J Otolaryngol 9:84-89

13. Minielly JA, Harrison EG, Fontana RS, Payne WS (1967) Verrucous squamous cell carcinoma of the esophagus. Cancer 20:2078-2087

14. Chute DJ, Stelow EB (2010) Cytology of head and neck squamous cell carcinoma variants. Diagn Cytopathol 38(1):65-80

15. Walvekar RR, Chaukar DA, Deshpande MS, Pai PS, Chaturvedi P, Kakade A, Kane SV, D’Cruz AK (2009) Verrucous carcinoma of the oral cavity: a clinical and pathological study of 101 cases. Oral Oncol 45(1):47-51

16. Pleat JM, Bradley M, Orlando A, Rigby H (2004) Verrucous carcinoma of the temporal bone: a wolf clothed in wool. Skull Base 14(1):39-46

17. Woodson GE, Jurco S, Alford BR, McGavaran MH (1981) Verrucous carcinoma of the middle ear. Arch Otolaryngol 107:63-65

18. Proops DW, Hawke WM, van Nostrand AWP, Harwood AR, Lunan M (1984) Verrucous carcinoma of the ear. Ann Otol Rhinol Laryngol 93:385-388

19. Edelstein DR, Smouha E, Sacks SH, Biller HF, Kaneko M, Parisier SC (1986) Verrucous carcinoma of the temporal bone. Ann Otol Rhinol Laryngol 95:447-453

20. Diengdoh JV, Leeming RD, Shaw MD (1990) Verrucous carcinoma of the base of the skull. Br J Neurosurg 4:73-76

21. Farrell ML, Dowe AC (1995) Verrucous carcinoma of the temporal bone. Aust N Z J Surg 65:214-216

22. Hagiwara H, Kanazawa T, Ishikawa K, Fujii T, Kitamura K, Noguchi Y, Iino Y (2000) Invasive verrucous carcinoma: a temporal bone histopathology report. Auris Nasus Larynx 27:179-183

23. Aydogan LB, Ozdemir S, Gumurdula D (2008) Verrucous carcinoma of the temporal bone. Am J Otolaryngol 29(1):69-71

24. Kletzker GR, Smith PG, McIntire LD, Leonetti JP (1995) Presentation and management of uncommon lesions of the middle ear. Am J Otol 16(5):634-642

25. Koch BB, Trask DK, Hoffman HT, Karnell LH, Robinson RA, Zhen W, Menck HR (2001) National survey of head and neck verrucous carcinoma: patterns of presentation, care, and outcome. Cancer 92(1):110-120

26. Orvidas LJ, Olsen KD, Lewis JE, Suman VJ (1998) Verrucous carcinoma of the larynx: a review of 53 patients. Head Neck 20:197-203

27. Pindborg JJ, Reichart PA, Smith CJ, van der Wall I (1997) Histological typing of cancer and precancer of the oral mucosa, 2nd edn. Springer, Berlin, pp 10-16

28. McCoy JM, Waldron CA (1981) Verrucous carcinoma of the oral cavity: a review of forty-nine cases. Oral Surg Oral Med Oral Pathol 52(6):623-629

29. Thompson LD (1997) Diagnostically challenging lesions in head and neck pathology. Eur Arch Otorhinolaryngol 254(8):357-366

30. Bouquot JE (1999) Oral verrucous carcinoma. Incidence in two US populations. Oral Surg Oral Med Oral Pathol Oral Radiol Endod 86(3):318-324

31. Ferlito A, Rinaldo A, Mannara GM (1998) Is primary radiotherapy an appropriate option for the treatment of verrucous carcinoma of the head and neck? J Laryngol Otol 112:132-139

32. Hagen P, Lyons GD, Haindel C (1993) Verrucous carcinoma of the larynx: role of human papillomavirus, radiation, and surgery. Laryngoscope 103:253-257

33. Edstrom S, Johansson SL, Lindstrom J, Sandin I (1987) Verrucous squamous cell carcinoma of the larynx: evidence for increased metastatic potential after irradiation. Otolaryngol Head Neck Surg 97:381-384

34. Lundgren JA, van Nostrand AW, Harwood AR, Cullen RJ, Bryce DP (1986) Verrucous carcinoma (Ackerman's tumor) of the larynx: diagnostic and therapeutic considerations. Head Neck Surg 9:19-26

35. Rider WD (1975) Toronto experience of verrucous carcinoma of the larynx. Can J Otolaryngol 4:278-279

36. O'Sullivan B, Warde P, Keane T, Irish H, Cummings B, Payne D (1995) Outcome following radiotherapy in verrucous carcinoma of the larynx. Int J Radiat Oncol Biol Phys 32:611-617

37. Huang SH, Lockwood G, Irish J, Ringash J, Cummings B, Waldron J, Kim J, Dawson LA, Bayley A, Hope A, O'Sullivan B (2009) Truths and myths about radiotherapy for verrucous carcinoma of larynx. Int J Radiat Oncol Biol Phys 73(4):1110-1115

38. Maurizi M, Cadoni G, Ottaviani F, Rabitti C, Almadori G (1996) Verrucous squamous cell carcinoma of the larynx: diagnostic and therapeutic considerations. Eur Arch Otorhinolaryngol 253:130135

39. Tharp ME 2nd, Shidnia H (1995) Radiotherapy in the treatment of verrucous carcinoma of the head and neck. Laryngoscope 105(4 Pt 1):391-396

40. McCaffrey TV, Witte M, Ferguson MT (1998) Verrucous carcinoma of the larynx. Ann Otol Rhinol Laryngol 107(5 Part 1):391-395

41. Cristalli G, Manciocco V, Pichi B, Marucci L, Arcangeli G, Telera S, Spriano G (2009) Treatment and outcome of advanced external auditory canal and middle ear squamous cell carcinoma. J Craniofac Surg 20(3):816-821

42. Kunst H, Lavieille JP, Marres H (2008) Squamous cell carcinoma of the temporal bone: results and management. Otol Neurotol 29(4):549-552 